\title{
Use of tellurite for the selection of verocytotoxigenic Escherichia coli 0157
}

\author{
P. M. ZADIK, P. A. CHAPMAN and C. A. SIDDONS
}

Public Health Laboratory, Herries Road, Sheffield S5 7BQ

\begin{abstract}
Summary. Potassium tellurite was assessed for the selection of verocytotoxigenic $\left(\mathrm{VT}^{+}\right)$ Escherichia coli O157. MICs were higher for $\mathrm{VT}^{+} E$. coli $\mathrm{O} 157$ than for other strains of E. coli and for Aeromonas spp. MacConkey medium containing sorbitol, tellurite and cefixime (TCSMAC) permitted the growth of $\mathrm{VT}^{+} E$. coli $\mathrm{O} 157$ and Shigella sonnei but partially or completely inhibited the growth of $67 \%$ of other strains of $E$. coli and all or most strains of other sorbitol-non-fermenting species tested. Of 391 rectal swabs from cattle screened on TCSMAC medium, 26 yielded isolates of $\mathrm{VT}^{+} E$. coli $\mathrm{O} 157$ whereas sorbitol-MacConkey medium with cefixime and rhamnose yielded only nine isolates. Inclusion of potassium tellurite in sorbitol-MacConkey agar markedly increased the rate of isolation of $\mathrm{VT}^{+} E$. coli O157 from cattle rectal swabs and may do so for other types of specimen.
\end{abstract}

\section{Introduction}

Strains of Escherichia coli that produce a potent cytotoxin active against cultured Vero cells are now recognised as important pathogens of man. ${ }^{1}$ These verocytotoxigenic $E$. coli (VTEC) strains have been associated with outbreaks and sporadic cases of haemorrhagic colitis (HC) in North America ${ }^{2,3}$ and England ${ }^{4,5}$ and with sporadic cases of haemolytic uraemic syndrome (HUS) in Canada ${ }^{6,7}$ and England. ${ }^{5,8}$ Both $\mathrm{HC}$ and HUS have been associated with high morbidity and mortality. ${ }^{9}$

Beef products and untreated milk have been suggested as possible sources of VTEC for man in North America. ${ }^{210}$ Verocytotoxin-producing $\left(\mathrm{VT}^{+}\right)$E. coli O157, the most common serogroup of VTEC isolated from man, has been isolated from cattle, ${ }^{5}$ although the route of transmission from cattle to man was not established. ${ }^{11}$ However, person-to-person transmission of $\mathrm{VT}^{+} E$. coli $\mathrm{O} 157$ has been documented..$^{12,13}$

Strains of $\mathrm{VT}^{+}$E. coli $\mathrm{O} 157$ do not ferment sorbitol, and sorbitol-MacConkey (SMAC) medium was devised to facilitate their isolation..$^{14}$ This medium is now widely used in clinical diagnostic laboratories. However, some $E$. coli strains of serogroups other than O157 are also sorbitol non-fermenters (NSF), as are members of several other genera found frequently in faeces of man and cattle, especially Proteus spp. and Aeromonas spp. Media have been developed to decrease the number of NSF colonies that need to be screened during the attempted isolation of $\mathrm{VT}^{+} E$. coli O157. These include cefixime/rhamnose/sorbitol MacConkey (CR-SMAC) medium, ${ }^{15}$ in which cefixime inhibits Proteus spp. at a concentration not inhibitory

Received 10 Dec. 1992; accepted 27 Jan. 1993. to $E$. coli and rhamnose is fermented by most NSF $E$. coli strains of serogroups other than O157, but not by $\mathrm{VT}^{+} E$. coli $\mathrm{O} 157$, and $\beta$-glucuronidase medium ${ }^{16}$ in which colonies of $\mathrm{VT}^{+} E$. coli can be detected by their lack of fluorescence. However, no medium has yet been described that allows the growth of $\mathrm{VT}^{+} E$. coli O157 while inhibiting other strains of E. coli, although immunomagnetic separation ${ }^{17}$ has been described as a method for the selective detection of $E$. coli $\mathrm{O} 157$ in food samples.

Tellurite has been used for 80 years for the isolation of pathogens including Corynebacterium diphtheriae, Staphylococcus aureus, Vibrio cholerae and Shigella spp. ${ }^{18,19}$ Initial testing in this laboratory (PHLS unpublished data) suggested it had a selective activity for $\mathrm{VT}^{+}$E. coli $\mathrm{O} 157$. The aim of this study was to investigate this activity further and to develop and evaluate a selective medium for $\mathrm{VT}^{+} E$. coli $\mathrm{O} 157$ based on tellurite resistance.

\section{Materials and methods}

\section{Bacterial strains}

For MIC studies, 38 strains of $\mathrm{VT}^{+} E$. coli $\mathrm{O} 157$ from human faeces, 38 strains of $\mathrm{VT}^{+} E$. coli $\mathrm{O} 157$ from cattle rectal swabs, 25 strains of non-O157 E. coli isolated from food, six strains of NSF non-O157 $E$. coli from cattle faeces, 39 strains of non-O157 E. coli from human faeces, 24 strains of Aeromonas spp. from human and animal sources together with human isolates of Proteus spp. (20), Morganella morganii (10) and Providencia (10) were tested. Nine strains of sorbitol-fermenting $E$. coli, randomly isolated from cattle rectal swabs, and one bovine strain of $\mathrm{VT}^{+} E$. coli $\mathrm{O} 157$ were used in the study to resolve mixed 
cultures. To study growth on media selective for $E$. coli O157, 315 strains of $\mathrm{VT}^{+} E$. coli $\mathrm{O} 157$ from human faeces, 82 strains of $\mathrm{VT}^{+} E$. coli $\mathrm{O} 157$ from cattle rectal swabs, 100 strains of non-O157 E. coli randomly isolated from human faeces, 22 strains of $S$. sonnei, 103 strains of Aeromonas spp. from human and animal sources, 26 strains of Proteus spp., 10 strains of Morganella morganii, 10 strains of Providencia spp. and eight strains of Plesiomonas spp. were tested; all were human isolates.

\section{Tellurite MICs}

A range of dilutions of potassium tellurite was prepared in 100- $\mu$ l volumes in 96-well microtitration plates (Sterilin), with MacConkey Broth (Oxoid CM5a) containing glucose $1 \%$ as diluent. Isolates to be tested were grown in nutrient broth at $37^{\circ} \mathrm{C}$ for $3 \mathrm{~h}$ and these cultures were diluted 1 in 100 in diluent to give an inoculum of $c .10^{5}$ organisms $/ \mathrm{ml} ; 100 \mu \mathrm{l}$ of inoculum were added to and mixed with each dilution of potassium tellurite (final concentrations $500-0.5 \mathrm{mg} / \mathrm{L}$ ). The plates were incubated at $37^{\circ} \mathrm{C}$ overnight. The lowest dilution of potassium tellurite that inhibited growth (no turbidity or colour change) was recorded as the MIC.

\section{Resolving mixed cultures}

One colony from each of nine bovine strains of sorbitol-fermenting $E$. coli and one NSF colony of $\mathrm{VT}^{+}$E. coli $\mathrm{O} 157$ were suspended together in $1 \mathrm{ml}$ of saline and $30 \mu \mathrm{l}$ of this suspension was added to $5 \mathrm{ml}$ of tryptone broth. A loopful of this was plated on to a series of SMAC plates containing a range of concentrations of potassium tellurite, from 10 to $0.02 \mathrm{mg} / \mathrm{L}$. These were incubated at $37^{\circ} \mathrm{C}$ overnight and examined for the number and appearance of sorbitol-fermenting and NSF colonies.

\section{Growth of strains on TC-SMAC medium}

TC-SMAC medium was prepared by supplementing SMAC medium (Oxoid, CM813) with potassium tellurite $2.5 \mathrm{mg} / \mathrm{L}$ (from filter-sterilised aqueous potassium tellurite $3.5 \%$ ) and cefixime $0.05 \mathrm{mg} / \mathrm{L}$. Strains were grown for $18 \mathrm{~h}$ in nutrient broth at $37^{\circ} \mathrm{C}$, diluted 1 in $10^{6}$ in nutrient broth and then applied with a multipoint inocular to TC-SMAC and SMAC plates to give $c .10^{2}$ organisms/spot inoculum. The plates were incubated for $18 \mathrm{~h}$ at $37^{\circ} \mathrm{C}$ and examined to determine whether growth on TC-SMAC was absent or markedly reduced with compared with growth on SMAC.

\section{Comparison of CR-SMAC and TC-SMAC for isolating $V T^{+} E$. coli $O 157$ from bovine rectal swabs}

Rectal swabs (391) were taken from cattle at an abattoir during an investigation of carriage of $\mathrm{VT}^{+} E$. coli O157. The swabs (Transwabs, Medical Wire Co.) were taken immediately after slaughter, transported to the laboratory on the same day and inoculated on to CR-SMAC medium ${ }^{15}$ (SMAC supplemented with cefixime $0.05 \mathrm{mg} / \mathrm{L}$ and rhamnose $0.5 \%$ ) and TCSMAC medium. The plates were incubated at $37^{\circ} \mathrm{C}$ overnight. Non-fermenting colonies were screened with a latex test ${ }^{20}$ for detecting $E$. coli $\mathrm{O} 157$ and latexagglutinating colonies were confirmed as $\mathrm{VT}^{+} E$. coli 0157 by agglutination to titre with $E$. coli $\mathrm{O} 157$ antiserum, standard biochemical tests, VT1 and VT2 gene probe tests and cell culture assay as described previously. ${ }^{5}$

\section{Results}

\section{Tellurite MICs of strains}

The potassium tellurite MICs of the strains tested are shown in table I. At a potassium tellurite concentration of $4 \mathrm{mg} / \mathrm{L} 56$ of 70 non-O157 strains of $E$. coli and 11 of $38 \mathrm{VT}^{+}$E. coli $\mathrm{O} 157$ strains from cattle were inhibited but all 38 strains of $\mathrm{VT}^{+}$E. coli $\mathrm{O} 157$ from human faeces grew.

\section{Resolving mixed cultures}

The incorporation of potassium tellurite $2.5 \mathrm{mg} / \mathrm{L}$ into SMAC gave the best inhibition of sorbitolfermenting colonies while preserving colonial size and number of colonies of the NSF strain of $\mathrm{VT}^{+} E$. coli O157.

\section{Effect of the addition of tellurite to SMAC on the growth of strains}

The results are shown in table II. Of 397 strains of $\mathrm{VT}^{+}$E. coli O157, all except one grew on TC-SMAC without significant reduction in size or number of colonies whereas 67 of 100 strains of non-O157 E. coli from human faeces either failed to grow or showed significant reduction in growth on TC-SMAC when compared to growth on SMAC. All 22 strains of $S$. sonnei grew on TC-SMAC but with somewhat reduced colonial size. The growth of almost all of the strains of the other NSF species tested was largely or completely inhibited on TC-SMAC.

\section{Comparison of CR-SMAC and TC-SMAC for isolating $V T^{+}$E. coli O157 from bovine rectal swabs}

When 391 bovine rectal swabs were cultured on TCSMAC medium, 26 isolates of $\mathrm{VT}^{+}$E. coli $\mathrm{O} 157$ were detected after 206 NSF colonies had been screened. However, when the swabs were cultured on CRSMAC medium, only nine isolates of $\mathrm{VT}^{+} E$. coli O157 were found after screening 47 NSF colonies. Eight of these nine strains had also been isolated on TC-SMAC. The difference in the number of isolates 
Table I. MICs of potassium tellurite for bacterial strains in broth

\begin{tabular}{l|ccc}
\hline \multicolumn{1}{c|}{ Organism } & Number tested & MIC $50(\mathrm{mg} / \mathrm{L})$ & MIC $90(\mathrm{mg} / \mathrm{L})$ \\
\hline VT $^{+}$E. coli O157 & & & \\
humans & 38 & 32 & 250 \\
$\quad$ cattle & 38 & 8 & 125 \\
$\quad$ Total & 76 & 32 & 125 \\
E. coli non-O157 & 70 & 2 & 16 \\
Proteus spp. & 20 & 500 & 500 \\
Morganella morganii & 10 & 125 & 1 \\
Providencia spp. & 10 & $\leqslant 0.5$ & 250 \\
Aeromonas spp. & 24 & $\leqslant 0.5$ & \\
\hline
\end{tabular}

Table II. Growth of bacterial strains on TC-SMAC compared with growth on SMAC

\begin{tabular}{l|cc}
\hline \multicolumn{1}{c|}{ Organism } & $\begin{array}{c}\text { Number of } \\
\text { strains tested }\end{array}$ & $\begin{array}{c}\text { Number without marked } \\
\text { inhibition of growth } \\
\text { on TC-SMAC }\end{array}$ \\
\hline Non-O157 E. coli from human faeces & 100 & 33 \\
VT $^{+}$E. coli O157 from human faeces & 315 & 314 \\
VT $^{+}$E. coli O157 from cattle faeces & 82 & 82 \\
Shigella sonnei & 22 & 22 \\
Proteus spp. & 26 & 0 \\
Morganella morganii & 10 & 0 \\
Providencia spp. & 10 & 0 \\
Aeromonas spp. & 103 & 5 \\
Plesiomonas spp. & 8 & 0 \\
& & \\
\hline
\end{tabular}

between the two media was significant $\left(\chi^{2}=8 \cdot 28\right.$, $\mathrm{p}<0.01)$.

\section{Discussion}

More sensitive methods for detecting $\mathrm{VT}^{+} E$. coli O157 in man, animals, food and the environment are required. Current methods rely on differential sugar fermentation and do not select $\mathrm{VT}^{+} E$. coli $\mathrm{O} 157$ from other strains of $E$. coli; therefore, they lack sensitivity. The new medium (TC-SMAC) gave substantial suppression of non-O157 strains and also inhibited such NSF bacteria as Proteus spp. by means of the cefixime, and Providencia spp. and Aeromonas spp. by means of the tellurite content. Rhamnose has been incorporated into CR-SMAC ${ }^{15}$ because its fermentation differentiated many NSF, non-O157 strains of E. coli from O157 strains. We did not incorporate rhamnose in the new medium because it would increase the cost substantially and the six NSF, non-O157 strains of $E$. coli tested were all inhibited by low concentrations of tellurite, suggesting that addition of rhamnose may not be necessary.

The suppression of non-O157 E. coli on TC-SMAC uncovered a large number of NSF colonies (206 among the 391 specimens) that required screening by latex agglutination for O157. This is a considerable increase over the 47 colonies that required screening from CRSMAC, albeit with a much increased yield in positive isolations from TC-SMAC. These non-O157 strains were not characterised further during the present study as they were of bovine origin and frequently cannot be identified by our standard range of biochemical tests. Characterisation could usefully be done in future to determine if other measures could suppress them or distinguish them from $\mathrm{VT}^{+}$E. coli $\mathrm{O} 157$ and to determine if some of them carry genes for verocytotoxin production.

The mechanism of tellurite resistance in $\mathrm{VT}^{+} E$. coli O157 is not known nor whether it is chromosomally or plasmid mediated. Tellurite resistance has been reviewed recently. ${ }^{21}$ Intrinsic resistance in Enterobacteriaceae is often plasmid mediated and usually involves plasmids belonging to the HI, $\mathrm{HII}$ and $\mathbf{P}$ incompatibility groups. Chromosomally-mediated resistance can be induced in tellurite-sensitive strains of E. coli. ${ }^{22}$ Possible mechanisms of resistance include reduced uptake via the phosphate transport pathway ${ }^{22}$ and reduction to metallic tellurium.

Although the aim was to improve isolation methods for $\mathrm{VT}^{+} E$. coli $\mathrm{O} 157$, it would be of interest to know whether verocytotoxigenic strains of other serotypes are also resistant to tellurite. Preliminary work on a small number of bovine strains of assorted serotypes suggests that some are resistant and some are not. However, most ferment sorbitol and TC-SMAC would not be useful for their isolation.

Tellurite is selective for $\mathrm{VT}^{+} E$. coli 0157 and markedly improved the rate of isolation from cattle rectal swabs. Further studies are needed with TCSMAC to determine whether it will improve isolation rates from human faeces and from food specimens. 


\section{References}

1. Karmali MA. Infection by verocytotoxin-producing Escherichia coli. Clin Microbiol Rev 1989; 2: 15-38.

2. Riley LW, Remis RS, Helgerson SD et al. Hemorrhagic colitis associated with a rare Escherichia coli serotype. $N$ Engl $J$ Med 1983; 308: 681-685.

3. Pai CH, Gordon R, Sims HV, Bryan LE. Sporadic cases of hemorrhagic colitis associated with Escherichia coli O157: H7. Ann Intern Med 1984; 101 : 738-742.

4. Smith HR, Rowe B, Gross RJ, Fry NK, Scotland SM. Haemorrhagic colitis and verocytotoxin-producing Escherichia coli in England and Wales. Lancet 1987; 1: 1062-1065.

5. Chapman PA, Wright DJ, Norman P. Verotoxin-producing Escherichia coli infections in Sheffield: cattle as a possible source. Epidemiol Infect 1989; 102: 439-445.

6. Karmali MA, Steele BT, Petric M, Lim C. Sporadic cases of haemolytic-uraemic syndrome associated with faecal cytotoxin and cytotoxin-producing Escherichia coli in stools. Lancet $1983 ; 1$ : 619-620.

7. Karmali MA, Petric M, Lim C, Fleming PC, Arbus GS, Loir H. The association between idiopathic hemolytic uremic syndrome and infection by verotoxin-producing Escherichia coli. J Infect Dis 1985; 151 : 775-782.

8. Scotland SM, Rowe B, Smith HR, Willshaw GA, Gross RJ. Vero cytotoxin-producing strains of Escherichia coli from children with haemolytic uraemic syndrome and their detection by specific DNA probes. J Med Microbiol 1988 ; 25: 237-243.

9. Spika JS, Parsons JE, Nordenberg D, Wells JG, Gunn RA, Blake PA. Hemolytic uremic syndrome and diarrhea associated with Escherichia coli $\mathrm{O} 157: \mathrm{H} 7$ in a day care center. J Pediatr 1986; 109: 287-291.

10. Martin ML, Shipman LD, Wells JG et al. Isolation of Escherichia coli $\mathrm{O} 157: \mathrm{H} 7$ from dairy cattle associated with two cases of haemolytic-uraemic syndrome. Lancet 1986; 2: 1043 .
11. Chapman PA, Jewes L., Siddons CA, Norman P, George SL. Verotoxin-producing Escherichia coli infections in Sheffield during 1989. PHLS Microbiol Digest 1990; 7: 163-166.

12. Ratnam S, March SB, Sprague WD, Severs D, Sullivan RM. Are humans a source of Escherichia coli $\mathrm{O} 157: \mathrm{H} 7$, the agent of hemorrhagic colitis? $N$ Engl J Med 1986; 315: $1612-1613$.

13. Carter AO, Borczyk AA, Carlson JAK et al. A severe outbreak of Escherichia coli O157: H7-associated hemorrhagic colitis in a nursing home. $N$ Engl J Med 1987; 317: 1496-1500.

14. March SB, Ratnam S. Sorbitol-MacConkey Medium for detection of Escherichia coli 0157: $\mathrm{H} 7$ associated with hemorrhagic colitis. J Clin Microbiol 1986; 23: 869-872.

15. Chapman PA, Siddons CA, Zadik PM, Jewes L. An improved selective medium for the isolation of Escherichia coli 0157. J Med Microbiol 1991; 35: 107-110.

16. Okrend AJG, Rose BE, Lattuada CA. Use of 5-bromo-5chloro-3-indoxyl- $\beta$-D-glucuronide in MacConkey sorbitol agar to aid the isolation of Escherichia coli O157: H7 from ground beef. J Food Protect $1990 ; 53$ : 941-943.

17. Okrend AJG, Rose BR, Lattuada CP. Isolation of Escherichia coli $\mathrm{O} 157$ : $\mathrm{H} 7$ using $\mathrm{O} 157$ specific antibody coated magnetic beads. J Food Protect 1992; 55: 214-217.

18. Shimada T, Sakazaki R, Fujimura S, Niwano K, Mishina M, Takizawa K. A new selective, differential agar medium for isolation of Vibrio cholerae O1: PMT (Polymyxinmannose-tellurite) agar. Jpn J Med Sci Biol 1990; 43: $37-41$.

19. Mujibur Rahaman M, Golam Morshed M, Sultanul Aziz KM, Munshi MMH. Improved medium for isolating shigella. Lancet $1986 ; 1$ : 271-272.

20. Chapman PA. Evaluation of a commercial latex slide test for identifying Escherichia coli O157. J Clin Pathol 1989; 42: 1109-1110.

21. Walter EG, Taylor DE. Plasmid-mediated resistance to tellurite: expressed and cryptic. Plasmid 1992; 27 : 52-64.

22. Tomás JM, Kay WW. Tellurite susceptibility and non-plasmidmediated resistance in Escherichia coli. Antimicrob Agents Chemother 1986; 30: 127-131. 